\title{
ANÁLISE DO ACORDO MERCOSUL-UNIÃO EUROPEIA SOB A SUA PERSPECTIVA HISTÓRICA NEGOCIAL: O PAPEL DOS ATORES NÃO ESTATAIS NO BRASIL
}

\author{
Joaner Campello de Oliveira Junior ${ }^{1}$ \\ Jamile Bergamaschine Mata Diz
}

\begin{abstract}
RESUMO:
Após 20 anos de negociação, a União Europeia e o MERCOSUL assinaram o acordo de livre comércio, englobando questões comerciais, matérias de natureza extracomercial como diálogo político e cooperação. Até a firma do acordo, o Brasil esteve governado por diferentes enfoques políticos, enquanto diversos atores não estatais, vinculados aos setores econômicos e políticos atuaram de forma positiva ou negativa para a concretização, conforme será analisado. Portanto, objetiva-se analisar a formação contextual do MERCOSUL e as tratativas com a União Europeia, o caminho percorrido para a conclusão do acordo, bem como as perspectivas comerciais e os fatores que contribuíram para concretizá-lo.
\end{abstract}

Palavras-Chave: Comércio Exterior. Integração Regional. MERCOSUL. União Europeia.

\section{ANALYSIS OF THE MERCOSUR- EUROPEAN UNION AGREEMENT UNDER ITS NEGOTIAL HISTORICAL PERSPECTIVE: THE ROLE OF NON-STATE ACTORS IN BRAZIL}

\begin{abstract}
After 20 years of negotiation, the European Union and MERCOSUR signed the free trade agreement, involving trade issues, non-comercial matters such as political dialogue and cooperation. Until the signing of the agreement Brazil was governed by different political approaches, while several non-state actors linked to the economic and political actors acted positively or negatively, as will be analyzed. Therefore, the objective is to analyze the context of the formation of MERCOSUR and the negotiations with the European Union, the path taken towards the conclusion of the agreement, such as the trade perspectives and the factors that contributed to its realization.
\end{abstract}

Keywords: Foreign Trade. Regional Integration. MERCOSUR. European Union.

\section{INTRODUÇÃO}

\footnotetext{
${ }^{1}$ Advogado. Pós-Graduado em Direito Público e Tributário pela AVM Educacional. Mestre em Direito das Relações Internacionais e da Integração Latino Americana pela Universidad de la Empresa - Uruguai. E-mail: joanercampello@hotmail.com.

2 Doutora em Direito Público/Direito Comunitário pela Universidad Alcalá de Henares - Madrid. Mestre em Direito pela UAH, Madrid Master en Instituciones y Políticas de la UE - UCJC/Madrid. Coordenadora da Cátedra Jean Monnet de Direito UFMG. Professora da Faculdade de Direito da Universidade Federal de Minas Gerais (UFMG). Professora da FDMC/MG. Coordenadora e professora do PPGD da Universidade de Itaúna. Coordenadora da Rede de Pesquisa “Integração, Estado e Governança”. E-mail: jmatadiz@yahoo.com.br
} 
A proposta de estabelecer um acordo de associação inter-regional entre o MERCOSUL e a União Europeia vem sendo negociada desde a década de 90. Durante o período de negociações foram abordados a questão comercial, a cooperação econômica e o diálogo político, com o escopo de intensificar as relações entre ambas as regiões.

No decurso do processo negocial diversos fatores de ordem externa, bem como a atuação de atores subnacionais e, também, não-estatais contribuíram ora positivamente, ora negativamente para que se estabelecesse um consenso que viabilizasse o referido acordo interregional.

Finalmente, após 20 anos de início das negociações, divulgou-se com entusiasmo a concretização do acordo como um marco a ser celebrado em face dos benefícios decorrentes para a região sul-americana, assim como para o país.

Não obstante, ao longo de todo o processo negocial percebe-se que a política e o comércio internacional têm passado por significativas mudanças, assim como atores estatais e não estatais, especialmente determinados setores políticos e econômicos, consoante será analisado no presente trabalho, participaram ativamente no intuito de se atingir o almejado acordo comercial. Neste sentido, o objetivo deste artigo será examinar a participação dos chamados atores não estatais, buscando verificar em que medida houve participação favorável ou não para a firma do Acordo birregional.

De outro lado, não se pode esquecer que entre o anúncio do fechamento do acordo e sua factual concretização há um caminho a ser percorrido para que seja validado e legislativamente reconhecido pelos pactuantes. Ademais, não se pode olvidar que os blocos regionais guardam assimetrias que afetam diversos atores públicos e privados.

Neste contexto, será inicialmente analisada a criação do MERCOSUL para, posteriormente, apresentar os desdobramentos históricos e políticos que levaram a à negociação com a União Europeia, dando ênfase à participação dos atores não estatais brasileiros, bem como analisar as perspectivas de comércio exterior para região sul-americana e, especificamente, para o Brasil. Assim, para a persecução do objetivo colimado será utilizado o método histórico e o dedutivo, com uso da técnica de pesquisa bibliográfica cujas fontes foram extraídas na literatura especializada digital e impressa. 


\section{UM BREVE RESUMO DA INTEGRAÇÃO REGIONAL SUL-AMERICANA E FORMAÇÃO DO MERCOSUL}

A integração regional não se resume aos países pertencentes ao espaço sulamericano, muito menos é recente. Em momento mais remoto as aspirações e as iniciativas para lograr a integração e cooperação não se iniciaram apenas pelos vizinhos sul-americanos, mas remontam aos movimentos de independência e a consolidação de Estados independentes no início do Século XIX (SUNKEL, 1998).

A ideia voltada para a integração do espaço americano, diga-se hispano-americano, nasce dos ideais de Simon Bolívar. Este, por meio da Carta da Jamaica, preconizava a unidade da América Hispânica independente e propunha a organização de uma confederação que se estenderia desde o México até a Argentina (MAGNOLI; ARAÚJO, 2003, p.14).

De outro turno, a primeira percepção brasileira para o horizonte da região sulamericana surge com o Barão do Rio Branco durante o período em que esteve à frente da Chancelaria brasileira (1902-1912), sugerindo a criação entre Argentina, Chile e Brasil de um instrumento legal que levasse a paz e a ordem na região (BUENO, 2012).

Mais tarde, Perón tentou o restabelecimento do Pacto ABC. Todavia, as diferenças políticas e de orientação diplomática hemisférica entre os três países sepultaram, rapidamente, essa tentativa de caráter mais hegemônico do que propriamente econômico ou comercial.

É importante frisar que entre a proposta do Pacto $\mathrm{ABC}$ até a formação do MERCOSUL diversas iniciativas surgiram no espaço latino-americano com o escopo de construir cada qual a sua forma e objetivo a integração regional, por exemplo, a ALALC (1960), a ALADI (1980), entre outras.

Após o início da década de 80 a retomada da ideia de integração, em particular, do espaço sul-americano contou com a participação dos dois países economicamente mais importantes da América do Sul, Argentina e Brasil. (DATHEIN, 2007). Embora esta retomada tenha contado com a participação ativa de ambos os países, faz-se necessário destacar que nem sempre o convívio entre estes foi pacífico. Neste aspecto, Oliveira (1998) destaca que o acirramento de forças decorrentes do militarismo brasileiro e argentino criou a ideia de um necessário enfrentamento de armas. Por outro lado, a disputa militar acrescentou significativos avanços na questão atômica, contribuindo para um ciclo lento e gradativo de cooperação com a finalidade de consolidar um projeto de integração nuclear. 
O fim dos governos militares e a redemocratização da Argentina (1983) e do Brasil (1985) deram novo impulso à reaproximação. Em 1985, os presidentes José Sarney e Raúl Alfonsín estabeleceram a Declaração de Iguaçu que iniciou um processo bilateral de consolidação democrática, privilegiando as relações comerciais, a complementação econômica e industrial e a cooperação tecnológica com ênfase na área nuclear.

No ano seguinte, em 1986, foi assinada a Ata para a Integração Brasil-Argentina que criou o Programa de Integração e Cooperação Econômica (PICE). Em 1988, foi assinado o Tratado de Integração, Cooperação e Desenvolvimento entre Brasil e Argentina com o propósito de estabelecer um mercado comum bilateral no intervalo de dez anos. Por fim, mediante a Ata de Buenos Aires (1990), os presidentes Collor (Brasil) e Menem (Argentina) se comprometeram a estabelecer um Mercado Comum bilateral até dezembro de 1994.

As negociações bilaterais despertaram as atenções de Uruguai e Paraguai que, decidiram participar do processo de integração, numa clara estratégia de aproximação econômica e política que culminou com a proposta de constituir um mercado comum no chamado Cone Sul (expressão utilizada por questões geográficas e territoriais). Assim, em 26 de março de 1991, foi criado o MERCOSUL por meio do Tratado de Assunção. É importante ressaltar que o Tratado estabelecia um período de transição até 31 de dezembro de 1994 em que os Estados-Partes se comprometiam a coordenar de forma gradual, flexível e equilibrada as suas políticas macroeconômicas de forma a possibilitar a implementação do Mercado Comum.

Em 1994 foi assinado o Protocolo de Ouro Preto que conferiu personalidade jurídica de direito internacional ao bloco. Inaugurou a estrutura institucional, pois estabeleceu normas de atuação para os órgãos mercosulistas, assim como determinou aqueles que possuiriam capacidade decisória, com natureza intergovernamental, a saber: o Conselho do Mercado Comum, o Grupo Mercado Comum e a Comissão de Comércio do MERCOSUL (art. $2^{\circ}$ ). Mais tarde, estabeleceu-se um sistema de solução de controvérsias, inicialmente previsto no POP, detalhado pelo Protocolo de Brasília, sendo este posteriormente derrogado pelo Protocolo de Olivos (2002). Estavam, portanto, dispostos os elementos estruturais institucionais e normativos para alcançar o objetivo fixado pelo Tratado de Assunção.

Embora o tratado constitutivo do bloco regional contenha a previsão de conformação de um Mercado Comum Regional até a atualidade, este objetivo não foi colimado, em que pese os esforços para realizá-lo. 
Vale ressaltar que, considerando os membros fundadores (Brasil, Argentina, Paraguai, Uruguai) e Venezuela (suspensa em 2017), o espaço integrado abrange territorialmente cerca de $72 \%$ (setenta e dois por cento) da América do Sul, equivalendo aproximadamente a três vezes o território da União Europeia. Em termos populacionais corresponde a $69,5 \%$ (sessenta e nove vírgula cinco por cento) da população sul-americana e economicamente a 76,2\% (setenta e seis vírgula dois por cento) do PIB da América do Sul, que se tomado em conjunto, equivaleria a $5^{\text {a }}$ (quinta) maior economia do mundo ${ }^{3}$ (Mercosul, 2019).

Atualmente, figuram como Estados-partes do MERCOSUL: Argentina, Brasil, Paraguai, Uruguai e Venezuela (suspensa). Enquanto os Estados Associados são: Chile, Colômbia, Equador, Guiana, Peru, Suriname e Bolívia. Não obstante, este último país esteja em processo de adesão ao bloco, vez que, o protocolo de adesão da Bolívia foi firmado pela totalidade dos Estados-partes em 2015 e aguarda a incorporação pelos respectivos Parlamentos nacionais.

Finalmente, como se pode observar no breve escorço histórico apresentado, apesar de contar com instrumentos normativos e institucionais mencionados, ainda não conseguiu lograr o objetivo de formação de um mercado comum.

\section{OS DESDOBRAMENTOS DA NEGOCIAÇÃO DO ACORDO ENTRE O MERCOSUL E A UNIÃO EUROPEIA}

A intenção dos países europeus em celebrar acordos de cooperação com os países que hoje integram o MERCOSUL e também os demais latino-americanos não é recente e antecede a própria formação do bloco do cone sul. Neste sentido, Carvalho e Leite (2013) exemplificam os Acordos Comerciais de Caráter não-preferencial firmados entre a Comunidade Econômica Europeia e a Argentina, em 1971; com o Uruguai, em 1973 e com o Brasil, em 1974, país que também firmou outro acordo de cooperação, em 1980. Tais acordos tiveram o mero objetivo de expandir os intercâmbios comerciais, excluindo qualquer outro aspecto de natureza extracomercial (DIZ; LUQUINI, 2011).

Todavia, enquanto a CEE na década de 70 avançava na construção de seu projeto de integração regional, na América Latina floresciam regimes ditatoriais, dificultando a proposta de integração regional (DIZ; LUQUINI, 2011).

\footnotetext{
${ }^{3}$ Disponível em <http://www.mercosul.gov.br/saiba-mais-sobre-o-mercosul>. Acesso de 31 de julho de 2019
} 
Além disso, durante o final da década de 70 e início dos anos 80, marcou-se um período economicamente negativo para os países latino-americanos. Enquanto os países centrais desenvolviam uma política econômica centrada na contenção da atividade econômica com o fito de enfraquecer os preços de matérias primas e os produtos primários, ao mesmo tempo estimulavam os países emergentes a manter suas economias abertas. Diante desta estratégia, os países desenvolvidos transferiam o ônus petróleo para as economias mais frágeis que, durante o supracitado período, sofreram forte endividamento externo e pressões inflacionárias. (MUNHOZ, 2002).

Neste contexto, os anos 80 acarretaram estagnação econômica na América Latina, comprometendo o seu desenvolvimento social e a sua inserção na economia mundial o que dificultou o desenvolvimento das relações com a Europa (DIZ; LUQUINI, 2011).

Com o inicio da década de 90 se desenha um novo cenário para a América Latina que viria a favorecer a intensificação da integração regional. Pelo prisma econômico a partir da segunda metade da década de 80 foram adotados programas de reformas econômicas com o objetivo de vencer a dívida externa, incentivos para atração de capital estrangeiro e um programa voltado para privatizações. Politicamente, o fim dos regimes ditatoriais ${ }^{4}$ permitiu a redemocratização dos países e a adoção de políticas de livre comércio e a retomada de processos de integração regional, com a consequente assinatura do Tratado de Assunção, conforme analisado anteriormente. Coincidindo com este contexto latino-americano, na Europa, ocorreu a assinatura do Tratado de Maastricht, 1992, que deu surgimento à União Europeia.

A partir da década de 90 os países da União Europeia passaram a adotar uma estratégia de maior aproximação com os países latino-americanos e os acordos passaram a ser ampliados com o intuito de realizar negociações, vis a vis, de natureza regional e não mais meramente individual, ou seja, país a país.

Logo após a assinatura do Tratado de Assunção, os chanceleres do MERCOSUL reuniram-se em Luxemburgo com o Presidente da Comissão Europeia com o escopo de lançar a ideia de um acordo Interinstitucional de cooperação, que se concretizou em 1992 por intermédio do Acordo de Cooperação Interinstitucional MERCOSUL/União Europeia que previa a cooperação em matéria de aduanas, normas técnicas e agricultura. (SAVINI, 2001)

\footnotetext{
${ }^{4}$ Exemplificativamente, na América do Sul vigoraram as seguintes ditaduras: Argentina (1966-1973, 19761983); Bolívia (19641982); Brasil (1964-1985); Chile (1973-1990); Equador (1972-1979); Paraguai (19541989); Peru (1968-1980) e Uruguai (1973-1985). (MACHADO; NÓBREGA, 2016).
} 
Em Madri, o MERCOSUL e a União Europeia firmaram o Acordo Quadro de Cooperação MERCOSUL-União Europeia, em 1995. Todavia, a expectativa em se chegar a uma conclusão no médio prazo terminou frustrada por diversas razões. A principal delas remetia-se à cautela do Brasil na criação de uma zona de livre comércio entre dois blocos em estágios diferentes de desenvolvimento econômico.

Ainda, pela ótica do MERCOSUL foram fatores negativamente influenciadores a consolidação da união aduaneira, a harmonização macroeconômica e as negociações com a ALCA. Enquanto, na União Europeia a implementação da União Econômica e Monetária, a ampliação em direção ao Leste Europeu, a reforma do próprio orçamento e da Política Agrícola Comum, como o aprofundamento das relações extracontinentais com a assinatura de acordo de livre comércio com a África do Sul (1999); México (2000) e a Convenção de Lomé (2000) com as ex-colônias na África e Caribe, foram fatores decisivos para que o Acordo não prosperasse. (SAVINI, 2001).

Em junho de 1996, durante o primeiro encontro de Chanceleres que conformavam a Comissão Mista MERCOSUL/UE definiu-se o papel e a composição da subcomissão comercial, responsável por preparar as negociações com base em três grupos de trabalho: bens, serviços, normas e disciplinas comerciais. Na primeira reunião, em dezembro de 1996, estabeleceu-se a necessidade imediata de realizar um mapeamento sobre o comércio birregional, a identificação de produtos prioritários e sensíveis de cada país e a definição dos grupos de trabalho dedicados à liberalização comercial. Já nesta ocasião, a questão agrícola começava a despontar como o grande problema para as negociações. Em julho de 1998, a Comissão Europeia formalizou perante o Conselho Europeu um pedido para dar início às negociações de um acordo de cooperação política, econômica que resultaria, posteriormente, na formação de uma área de livre comércio birregional. Não obstante, durante os debates prévios à negociação, o representante francês alertara que o acordo com o bloco sulamericano representaria um vultoso custo adicional para a Política Agrícola Comum (PAC). (SAVINI, 2001).

Destarte, as críticas e as pressões de alguns países europeus liderados pela França colaboraram para obstaculizar as negociações. Além disso, a desvalorização do real em janeiro de 2009 que afetou profundamente a integração mercosulista, bem como o fracasso da Rodada do Milênio da OMC foram elementos que contribuíram para tornar incerto o futuro das negociações, postergando o início dos trabalhos para a elaboração do Acordo. 
Em 1999, ocorreu na cidade do Rio de Janeiro a Primeira Cúpula União Europeia América Latina - Caribe com o escopo de fortalecer as relações e fincar o marco do futuro Acordo birregional. Com o término da Cúpula foi assinada a Declaração do Rio, documento que formalizou a vontade de promover um maior desenvolvimento e diversificação do comércio entre os blocos, levando em consideração as negociações multilaterais e bilaterais, futuras e em curso, para a liberalização do comércio, em particular, da União Europeia com o MERCOSUL.

O período compreendido entre 2000 e 2004 foi marcado pela primeira fase de negociações com a elaboração de textos preliminares e as trocas de ofertas que foram consideradas insatisfatórias. No segundo semestre de 2004, a UE propôs a liberalização de 94\% (noventa e quatro por cento) do comércio global, mas não contemplou o livre comércio de produtos agrícolas.

É importante ressaltar que a partir do ano 2000 foram realizadas diversas reuniões de Cúpula União Europeia - América Latina e Caribe ${ }^{5}$. Estas reuniões indicaram uma tendência crescente de aproximação e a vontade de cooperação regional em diversos temas como ciência e tecnologia, direitos humanos, o apoio ao desenvolvimento sustentável, multilateralismo, etc. Sem embargo, após a Sexta Cúpula surgiram os avanços mais significativos no âmbito dos acordos de associação, quando se decidiu pela retomada das negociações entre a União Europeia e o MERCOSUL ${ }^{6}$ com vistas a formalizar um acordo de associação birregional. (DIZ; LUQUINI, 2011).

Com o relançamento das negociações birregionais os impasses permaneceram em razão da dificuldade que as partes tiveram em oferecer aberturas significativas nos seus respectivos setores econômicos, especialmente aqueles considerados sensíveis como a produção agrícola. Diante deste quadro, no período compreendido entre 2010 e 2012 estabeleceu-se uma segunda fase de negociações que não conseguiu prosperar devido aos entraves já mencionados, e entre 2016 e 2019 iniciou-se a terceira fase de negociações, que

\footnotetext{
${ }^{5}$ Madri (2002), México (2004), Viena (2006), Lima (2008), Madri (2010).

${ }^{6}$ Em relação ao MERCOSUL, até o ano de 2005, foram realizadas dezesseis rodadas de negociações bilaterais: $1^{\mathrm{a}}$ rodada - abril de 2000, em Buenos Aires; $2^{\mathrm{a}}$ rodada - junho de 2000, na Bélgica; $3^{\mathrm{a}}$ rodada - novembro de 2000, em Brasília; $4^{\mathrm{a}}$ rodada - março de 2001, em Buenos Aires; $5^{\mathrm{a}}$ rodada - julho de 2001, em Montevidéu; $6^{\mathrm{a}}$ rodada - outubro de 2001, na Bélgica; $7^{\mathrm{a}}$ rodada - abril de 2002, em Buenos Aires; $8^{\mathrm{a}}$ rodada - novembro de 2002, em Brasília; $9^{\mathrm{a}}$ rodada - março de 2003, em Bruxelas; $10^{\mathrm{a}}$ rodada - junho de 2003, em Assunção; $11^{\mathrm{a}}$ rodada - dezembro de 2003, em Bruxelas; $12^{\mathrm{a}}$ rodada - março de 2004, em Buenos Aires, $13^{\mathrm{a}}$ rodada - maio de 2004, em Bruxelas, $14^{\mathrm{a}}$ rodada - junho $2004,15^{\mathrm{a}}$ rodada - outubro de 2004, em Luxemburgo e, finalmente, a $16^{\mathrm{a}}$ rodada - setembro de 2005, em Bruxelas.
} 
culminou, em 28 de junho de 2019, com o anúncio dos Ministros do MERCOSUL e dos comissários da União Europeia, em Bruxelas, da conclusão da parte comercial do Acordo de Associação MERCOSUL-UE.

Os pilares estabelecidos no acordo centraram-se no diálogo político, na cooperação e no livre comércio, sendo composto de capítulos e anexos referentes aos seguintes temas: acesso tarifário ao mercado de bens (compromissos de desgravação tarifária); regras de origem; medidas sanitárias e fitossanitárias; barreiras técnicas ao comércio (anexo automotivo); defesa comercial; salvaguardas bilaterais; defesa da concorrência; facilitação de comércio e cooperação aduaneira (protocolo de assistência e cláusula antifraude); serviços e estabelecimentos (compromissos em matéria de acesso); compras governamentais (compromissos em matéria de acesso); propriedade intelectual (indicações geográficas); integração regional; diálogos; empresas estatais; subsídios; pequenas e médias empresas; comércio e desenvolvimento sustentável; anexos de vinhos e destilados; transparência; temais institucionais, legais e horizontais e solução de controvérsias.

Segundo dados oficiais os blocos somados representam um PIB de cerca de US\$ 20 trilhões (vinte trilhões de dólares americanos) e um mercado aproximado de 780 milhões de pessoas. Comercialmente, a UE é o segundo parceiro comercial do bloco sul-americano, ao passo que este é o oitavo parceiro comercial extra regional da União Europeia. Particularmente, $18 \%$ (dezoito por cento) do total exportado pelo Brasil em 2018 teve como destino o bloco europeu (ITAMARATY, 2019).

Antes do acordo, apenas $24 \%$ das exportações brasileiras entravam livres de tarifas na UE. Após a desgravação prevista no acordo, 92\% das importações do MERCOSUL e 95\% das linhas tarifárias entrarão livres de tarifas na UE. O MERCOSUL, por sua vez, liberalizará 91\% das importações originárias da UE e 91\% das linhas tarifárias após a desgravação prevista no acordo (ITAMARATY, 2019).

Mormente, para que o acordo venha a produzir efeitos deverá ser seguido um trâmite estabelecido pelos sistemas jurídicos dos pactuantes. Para isso, o texto sofrerá uma revisão e a tradução para as línguas oficiais dos Estados pactuantes. A partir da sua tradução e revisão o texto será encaminhado pela Comissão Europeia ao Conselho da UE para que realize a assinatura formal e a votação no Parlamento Europeu e, a depender, da matéria, pelos Parlamentos nacionais dos Estados-membros ou instância equivalente, conforme previsto nos respectivos ordenamentos internos. Por outro lado, cada Estado parte do MERCOSUL deverá 
realizar o respectivo processo interno para a ratificação do acordo que, no caso brasileiro, significa a assinatura pela Presidência da República e a aprovação pelo Congresso Nacional para a apreciação tanto pela Câmara dos Deputados, como pelo Senado Federal, com a consequente promulgação pelo Executivo.

De conseguinte, até a entrada em vigor há um longo caminho a ser percorrido, o que poderá provocar possíveis conflitos. Em primeiro lugar, a pressão costumeira dos agricultores europeus, em especial, os produtores de gado que temem sair prejudicados com a vigência do acordo. Além disso, as eleições europeias podem ser um prelúdio de mudanças no Parlamento Europeu, bem como as eleições nacionais tanto para os Parlamentos como para os Poderes Executivos, além da onda de movimentos contrários à integração. Diante deste contexto, é preciso aguardar os desdobramentos para que se possa realmente afirmar que o Acordo seguirá adiante, nos moldes então acertados.

Não se deve olvidar que durante o longo período de negociação entre os dois blocos, até a confirmação do acordo birregional, diversos acontecimentos no sistema internacional tiveram o condão de influenciar os atores ora para o avanço, ora para a estagnação da negociação.

O atentado de 11 de setembro de 2011, nos Estados Unidos, inseriu a luta internacional contra o terrorismo no debate internacional e trouxe a preocupação em relação ao tema para a agenda de política exterior Europeia. Por outro aspecto, o avanço chinês sobre as economias do MERCOSUL aliado a ao prolongamento da crise econômica e financeira de 2008 representou a perda de espaço comercial europeu no subcontinente como pode se observar pela seguinte tabela:

Tabela 01 - Exportações/ Importações MERCOSUL - principais parceiros

\begin{tabular}{|c|c|c|c|c|}
\hline \multicolumn{5}{|c|}{ Exportações Totais MERCOSUL - milhares U\$S } \\
\hline Ano & China & EUA & EU & MERCOSUL \\
\hline 2008 & 23.197 .924 & 34.054 .963 & 62.355 .645 & 50.289 .534 \\
\hline 2015 & 35.173 .332 & 22.277 .055 & 36.180 .975 & 35.085 .649 \\
\hline 2016 & 40.470 .482 & 28.167 .770 & 44.000 .463 & 37.386 .343 \\
\hline 2017 & 53.329 .296 & 31.875 .573 & 45.617 .006 & 40.998 .044 \\
\hline 2018 & 65.731 .842 & 29.347 .911 & 43.762 .444 & 28.347 .554 \\
\hline \multicolumn{5}{|c|}{ Importações Totais MERCOSUL - milhares U\$S } \\
\hline 2008 & 36.647 .545 & 47.177 .699 & 54.002 .441 & 51.680 .169 \\
\hline 2015 & 47.910 .254 & 37.023 .190 & 50.550 .703 & 34.497 .300 \\
\hline
\end{tabular}




\begin{tabular}{|l|l|l|l|l|}
2016 & 39.075 .368 & 33.125 .519 & 44.262 .735 & 33.647 .387 \\
\hline 2017 & 45.254 .720 & 35.516 .076 & 47.308 .410 & 39.451 .837 \\
\hline 2018 & 41.706 .553 & 32.192 .699 & 38.610 .289 & 28.639 .093 \\
\hline \multicolumn{5}{|c|}{ Fonte: ALADI, 2019}
\end{tabular}

No entanto, a queda do crescimento da China e o consequente fim do boom das commodities torna atrativo o acordo com a UE, pois possibilita estabelecer o acesso de produtos agrícolas sul-americanos em território europeu, estimulando o aumento das exportações. Acresce-se a isso a pressão do avanço dos mega acordos preferenciais, que podem vir a causar impactos no comércio dos países não inseridos, bem como o interesse manifesto do Uruguai por ocasião da ocupação da Presidência Pró-Tempore em retomar os contatos MERCOSUR-China para determinar a melhor forma de relacionamento no plano econômico-comercial. (SANTOS; MENGANA, 2016), (MERCOSUL, 2018).

\section{A ATUAÇÃo dOS ATORES NÃO-ESTATAIS NO BRASIL PARA O ACORDO MERCOSUL-UNIAO EUROPEIA}

Com o florescimento da década de 90, após a eleição de Fernando Collor de Mello se iniciava um novo ciclo no país voltado para a abertura econômica e pelo processo de privatização de empresas públicas. Neste período, encerrou-se um ciclo de políticas destinadas a estimular a produção e os negócios voltados para o mercado interno. Assim, o governo Collor promoveu mudanças pró-mercado em conformidade com as diretrizes estabelecidas no Consenso de Washington.

Todavia, as medidas adotadas como a mudança da moeda nacional, o confisco da poupança e a entrada de uma avalanche de produtos importados, em especial no setor de informática, atingiram tanto o mercado consumidor interno, como também a indústria brasileira, que imediatamente apresentou retração de suas atividades. Diante deste contexto, as empresas nacionais passaram a flexibilizar o discurso de abertura, defendendo maior gradualismo. (MATHIAS, 2011).

Com o impeachment de Fernando Collor, Itamar Franco (1992-1995) assumiu a presidência e manteve o processo de liberalização iniciado por Collor, porém, atenuado e com salvaguardas para setores específicos da indústria brasileira. Em 1995, foi eleito Fernando Henrique Cardoso (1995-2003), Ex-ministro da Fazenda de Itamar Franco, quem manteve a política de abertura econômica do país, bem como o processo de privatizações de estatais. 
No contexto internacional, a gestão FHC privilegiou as relações com os Estados Unidos e, em alguma medida, com a União Europeia, em detrimento das relações sul-sul, embora o MERCOSUL tenha sido utilizado como espaço de disputa politica e econômica (MATHIAS, 2011).

Em 1996, foi criada a Coalização Empresarial Brasileira (CEB) voltada para a participação de empresas ou organizações empresariais com a finalidade de exercer a mediação nas negociações comerciais internacionais, a partir do consenso interno, por meio do diálogo com o governo brasileiro e de seus representantes legais ${ }^{7}$.

A Confederação Nacional das Indústrias (CNI) ao assistir o processo de abertura comercial e econômica da década de 90 , passou a pressionar o governo visando à melhoria dos índices de competitividade da indústria brasileira, a partir dos gargalos do país, como a infraestrutura precária. (BISPO, 2017). Enquanto defendia a importância da celebração de acordos de comércio para induzir o aumento do fluxo comercial, de investimentos, a competitividade e o crescimento econômico, também, reconhecia-se o potencial de causar prejuízos a diversos setores. (AEB, 2013).

No período compreendido entre 1990 e o início dos anos 2000, o Brasil esteve envolvido em diferentes rodadas de negociações tendo em vista a abertura dos mercados brasileiros com as negociações no âmbito da OMC, da ALCA e da União Europeia. A consumação destes acordos afetaria os setores nacionais menos competitivos, o que despertou no empresariado a defesa de seus interesses, passando a exigir do governo brasileiro que trabalhasse para o ganho de competitividade das empresas nacionais face às estrangeiras.

Enquanto o setor industrial demonstrava preocupação com o grau de abertura a ser adotado pelo país, por sua vez, o setor agropecuário visava destravar barreiras tarifárias e não tarifárias criadas pelos países desenvolvidos, em particular, a União Europeia com sua respectiva aplicação da Política Agrícola Comum. (BISPO, 2017).

Em 2004, durante as negociações entre MERCOSUL e UE, o bloco europeu propôs abrir 94\% (noventa e quatro por cento) do seu comércio, ao passo que os bens industriais do MERCOSUL, gradualmente, teriam as tarifas de importação liberalizadas em quase a sua

\footnotetext{
${ }^{7}$ Vale ressaltar que integram a CEB a Confederação do Comércio (CNC), a Confederação das Instituições Financeiras (CNIF), a Confederação da Agricultura (CNA) e a Confederação dos Transportes (CNT), a Associação de Comércio Exterior do Brasil (AEB), A Confederação Nacional da Indústria (CNI) e o Conselho de Empresários da América Latina (CEAL).
} 
totalidade. Não obstante, os produtos sensíveis exportados pelo bloco sul-americano despertaram relevante polêmica.

$\mathrm{Na}$ verdade, durante o processo negocial a UE evitava a abertura do seu setor agrícola, enquanto o MERCOSUL protegia seu setor industrial. Este impasse claramente se refletia nas incertezas que a CNI e a Confederação Nacional da Agricultura (CNA) nutriam quanto ao fechamento do acordo. Neste sentido, o representante da CNA, Gilman Viana achava frágil a proposta europeia e julgava que era melhor não concluir o acordo no prazo estabelecido, ou conclui-lo mesmo de forma menos intensa (SANTOS, 2017). Já a indústria adotou posição mais precavida, defendendo um cronograma lento e gradual em razão da diferença de competitividade industrial entre os dois blocos.

Mesmo com o impasse, várias fases de negociações ocorreram sem que se estabelecesse um consenso a ponto de permitir o fechamento do acordo entre os blocos. No entanto, a partir de 2012, uma conjuntura de fatores contribuiu para que a burguesia interna passasse mais intensamente a questionar a política externa brasileira e a política sul-sul, dentre eles: a diminuição do PIB; o aumento das barreiras comerciais na Argentina devido à crise econômica e política para a proteção da indústria; a criação da Aliança do Pacífico como uma forma de disputar o comércio do MERCOSUL, da UNASUL e o papel da China; o golpe de Estado no Paraguai que dá início à crise dos governos progressistas na região e o aumento das importações chinesas na região, disputando mercado com a burguesia brasileira. (BERRINGER; FORLINI, 2018).

Em 2014, no rol de propostas de Integração Externa da Indústria, produzido pela FIESP já se manifestava o interesse desta entidade em promover um processo de readequação da estrutura e da operação do MERCOSUL, de forma a que este se tornasse em um instrumento de inserção internacional, e não apenas sub-regional. Além disso, colocava como prioridade de política externa brasileira a finalização do Acordo MERCOSUL - União Europeia até o início de 2015 (FIESP, 2014).

A partir da reeleição de Dilma Rousseff, no pleito eleitoral de 2014, o governo padeceu com críticas e um processo de desgaste interno a ponto de paralisá-lo. Esta paralisia e a fragmentação da frente neodesenvolvimentista, particularmente, a partir do impeachment de 2016 levaram a parte do setor econômico interno a criticar a política regional brasileira. (BERRINGER; FORLINI, 2018). Tanto que o processo de impeachment recebeu apoio das lideranças políticas no Congresso Nacional e de entidades empresariais como a Confederação 
Nacional de Transportes (CNT) e a Confederação da Nacional da Indústria (CNI) sob o argumento da necessidade do ajuste fiscal e diversas reformas, dentre elas, a trabalhista e previdenciária. (MANFRINI; WARTH, 2016).

Com o desfecho do impeachment, Michel Temer assumiu a Presidência da República cujo partido já havia divulgado, em 2015, o Programa Uma Ponte para o Futuro com o escopo de preservar a economia nacional e viabilizar o seu desenvolvimento.

Notoriamente, no cenário de concorrência global, a redução dos custos mediante cortes e diminuição da força de trabalho é um pressuposto da recuperação e expansão dos lucros. Vale ressaltar que o Brasil, nos anos 90, já havia experimentando o discurso de liberalização comercial e a estratégia de desregulamentação do mercado de trabalho, primando por alterações na legislação trabalhista (CARDOSO JR, 2002). Segundo Mathias (2011) a CNI desde a década de 90 defendia a desregulamentação econômica; a revisão da legislação trabalhista; a redução da taxa de juros para financiamentos e empréstimos na rede bancária; a revisão da carga tributária; melhoria da infraestrutura nacional; de forma a promover, segundo tal órgão, competitividade frente ao mercado externo.

Com Temer à frente do Poder Executivo são postas em prática, no sistema jurídico e político brasileiro, as premissas do programa uma ponte para o futuro, de caráter neoliberal. Dentre as medidas, retorna à agenda política nacional a questão da reforma trabalhista, embora o documento anteriormente citado Ponte para o Futuro aponte no Relatório Global de Competividade 2015-2016 feito pelo Fórum Econômico Mundial que o maior dos problemas para a realização de negócios com o país seja o nível dos impostos e a complexidade tributária, correspondendo a $25 \%$ (vinte e cinco por cento), enquanto a legislação trabalhista apresenta um percentual de 12\% (doze por cento). (FUNDAÇÃO ULYSSES GUIMARÃES, 2015).

Não obstante, o que se presenciou foi à promulgação da Lei $n^{\circ} 13.467 / 2017$, alterando diversos aspectos na Consolidação das Leis do Trabalho cujas modificações poderão trazer resultados diferentes do propagandeado, por exemplo, a retomada do emprego que ainda hoje patina no Brasil.

Sob o ponto de vista comercial, o documento Ponte para o Futuro menciona em todo o seu texto, apenas uma única vez o MERCOSUL, tornando nítida a mudança de orientação política e comercial. No documento, menciona-se a intenção de realizar maior abertura comercial e a busca de acordos comerciais com Estados Unidos, União Europeia e Japão com 
ou sem a companhia do MERCOSUL, embora manifeste o interesse preferencial de realizálos em conjunto com o bloco sul-americano. (FUNDAÇÃO ULYSSES GUIMARÃES, 2015).

É importante ressaltar que o Chanceler José Serra, cuja nomeação foi bem recebida pela Confederação Nacional da Indústria $(\mathrm{CNI})$, durante o seu discurso de posse na Casa de Rio Branco, apresentou dez diretrizes que estabeleciam os pilares da nova política externa brasileira, e aproveitou para criticar as gestões anteriores ao dizer a que não serviria de "conveniências e preferencias ideológicas de um partido político e de seus aliados no exterior”. (ITAMARATY, 2016).

Em 2017, no portal web da Confederação Nacional da Indústria, já se destacava a retomada das negociações comerciais entre o MERCOSUL e a União Europeia, afirmando que os acordos comerciais voltariam à agenda política externa brasileira, em razão da pressão do empresariado ao reclamar que o país ficou fora das negociações consideradas estratégicas, caso dos acordos comerciais birregionais, e perdeu preferência e acesso a importantes mercados.

Finalmente, em nota oficial, a FIESP menciona a assinatura do acordo inter-regional como um marco histórico a ser festejado, rememorando que a organização atua desde 2010 em prol das negociações entre os blocos. Todavia, mostra desconhecer os termos ajustados, pois afirma que aguarda a divulgação dos detalhes finais para que seja avaliado o impacto deste em cada um dos setores da economia brasileira, reiterando que o governo brasileiro passa a ter a obrigação de reduzir o custo Brasil para que as empresas nacionais tenham condições de competir com as empresas europeias (FIESP, 2019).

É evidente que um acordo desta envergadura tende a beneficiar, principalmente os setores agroexportadores sul-americanos em razão do resfriamento do ciclo de commodities para a China. Isso facilmente se comprova, observando o fluxo comercial entre Brasil e União Europeia, onde as exportações de bens primários são impactantes, ao passo que no lado das importações a União Europeia se beneficia do escoamento de produtos manufaturados e semimanufaturados.

Gráfico 1 - Exportações brasileiras por fator agregado - União Europeia 
Fonte: MDIC, 2019

Ademais, desde a última Assembleia Constituinte que culminou com a entrada em vigor da Constituição de 1988 há o embate de dois seguimentos antagônicos voltados para setor agrícola no Brasil. De um lado, o Movimento Sem Terra (MST), fundado em 1984, e de outro a União Democrática Ruralista (UDR) composta de grandes e médios proprietários de terras, criada em 1985. (LOCATEL; LIMA, 2016).

Deste embate de forças antagônicas não se pode olvidar o peso político das estruturas voltadas para o agronegócio representadas pela Confederação Nacional de Agricultores (CNA) e pela Frente parlamentar da Agropecuária (FPA) que possui atualmente 32 (trinta e dois) senadores e 235 (duzentos e trinta e cinco) deputados no Congresso Nacional ${ }^{8}$.

A pujança do setor agrário na vida política brasileira pode ser observada por dois cruciais aspectos. Primeiramente, a partir dos dados do financiamento agropecuário, onde aproximadamente $80 \%$ (oitenta por cento) dos recursos públicos são apropriados pelos segmentos empresariais que representam menos de $20 \%$ (vinte por cento) dos estabelecimentos agropecuários brasileiros. (LOCATEL; LIMA, 2016). Em segundo plano, a influência na propositura do processo voltado para a defesa dos interesses do setor, tais como: restrição aos direitos das populações indígenas (OLIVEIRA JUNIOR; VAZ, 2017); nos PL 6.299/2002 e PL 3.200/15 que revogam a Lei dos Agrotóxicos 7.802/89, causando embates entre os ruralistas e órgãos de controle ambiental e sanitário; o PL 2.362/2019 que revoga, no Código Florestal, as áreas de reserva legal, a fim de possibilitar a exploração econômica dessas áreas; na proposta do Ministério do Meio Ambiente em fazer uma revisão das 334 (trezentos e trinta e quatro) unidades de conservação ambiental existentes no país administradas pelo $\mathrm{ICMBIO}^{9}$; na ambiguidade do governo brasileiro sobre a permanência ou não no Acordo de Paris, dentre outros.

Embora o acordo MERCOSUL-União Europeia desperte o interesse do setor agroexportador brasileiro, especialmente, o pecuário, não se deve deixar de observar que estão

\footnotetext{
${ }^{8}$ Disponível em <https://www.camara.leg.br/internet/deputado/frenteDetalhe.asp?id=53910>. Acesso em $31 \mathrm{de}$ agosto de 2019.

${ }^{9}$ Instituto Chico Mendes de Conservação Ambiental
} 
previstas contrapartidas para a sua concretização ${ }^{10}$. Neste sentido, contempla o compromisso das partes com a proteção do clima e do meio ambiente com base na sustentabilidade, na conservação da biodiversidade e na implementação do Acordo de Paris, entre outros aspectos. No caso deste último há a previsão de combater o desmatamento ilegal, inclusive, no bioma Amazônico que, recentemente, foi razão de embate entre o INPE e o governo brasileiro devido à publicação de dados que constatam aumento de $88 \%$ (oitenta e oito por cento) no desmatamento da Amazônia, comparado com dados do mesmo período do ano anterior.

De outra forma, estabelece a proteção dos direitos dos trabalhadores, como a proibição de trabalhos forçados ou infantil, a não discriminação no ambiente de trabalho, a liberdade de associação e o direito de negociação coletiva, a proteção dos direitos humanos e das minorias, todos esses princípios considerados expressamente como valores da UE previstos no Tratado de Lisboa. Sem embargo, a legislação nacional parece caminhar no sentido contrário, seja com a reforma trabalhista, ou com o desejo manifesto em realizar mudanças nas normas regulamentadoras da segurança do trabalho sob a justificativa de economia para o setor privado e aumento da produtividade. Inclusive, deve ser ressaltado que a Organização Internacional do Comércio (OIT) se manifestou de forma contrária à reforma trabalhista consagrada na Lei $\mathrm{n}^{\circ} 13.467 / 2017$ por colisão frontal com suas Convenções Internacionais já adotadas pelo Brasil.

Ademais, o acordo não implica abertura imediata, mas estabelece prazos para a redução das tarifas da União Europeia. O agronegócio terá liberalização imediata ou quase imediata de 99\% (noventa e nove por cento) das importações agrícolas ao MERCOSUL. No entanto, as tarifas de importação serão eliminadas total ou parcialmente para produtos específicos como 81,7\% (oitenta e um vírgula sete por cento) para suco de laranja, frutas, café solúvel, peixes e óleos vegetais, havendo ainda previsão de cotas ou preferências fixas de $17,7 \%$ (dezessete vírgula sete por cento), por exemplo, para carnes bovinas, suínas, de aves, açúcar, etanol, etc. ${ }^{11}$

Embora o agronegócio tenha demonstrado entusiasmo e boas perspectivas para o comércio exterior brasileiro, os produtores europeus ainda se mostram reticentes e prometem exercer pressão nos respectivos parlamentos nacionais para que o acordo somente entre em

\footnotetext{
${ }^{10}$ Disponível em <http://trade.ec.europa.eu/doclib/docs/2019/june/tradoc_157957.pdf〉. Acesso em 01 de agosto de 2019.

${ }^{11}$ Disponível em Acesso em <https://www.cnabrasil.org.br/assets/arquivos/Acordo-MS-UE-1.pdf>. 02 de agosto de 2019
} 
vigor, caso não venham a sofrer perdas significativas com a invasão de produtos agrícolas de origem do MERCOSUL.

A preocupação e oposição dos produtores europeus não são recentes, pois já havia sido demonstrado receio nas negociações pretéritas, sobretudo por parte da França, ao afirmar, desde o início das negociações, que o acordo colocaria em risco a Política Agrícola Comum $(\text { PAC })^{12}$. (SANTOS, 2017).

De certo modo, não se pode dizer que o temor é desmedido. Basta observar que alguns países da UE, em 2018, produziram quase a totalidade de produtos intrazona, os mesmos que receberão cotas preferenciais para comercialização na Europa pelo MERCOSUL, a partir da vigência do acordo, conforme tabela abaixo.

Tabela 02 - Produção Agrícola países UE - principais produtores

\begin{tabular}{|c|c|c|c|c|}
\hline \multicolumn{5}{|c|}{ Produção Agrícola - \% Total } \\
\hline País & Leite cru & Carne Bovina & Carne Suína & Aves \\
\hline Alemanha & 19,2 & 14,4 & 23,3 & 10,4 \\
\hline Áustria & 2,2 & 2,9 & 2,2 & 1 \\
\hline Bélgica & 2,4 & 3,6 & 4,5 & 3,2 \\
\hline Dinamarca & 3,2 & 1,6 & 6,3 & 1 \\
\hline Espanha & 4,9 & 8,3 & 18,4 & 10,5 \\
\hline França & 15,3 & 18,5 & 9,3 & 11,4 \\
\hline Holanda & 8,4 & 5,6 & 6,2 & 8 \\
\hline Irlanda & 4,4 & 7,9 & 1,3 & 1 \\
\hline Itália & 7,6 & 9,7 & 6,3 & 9,2 \\
\hline Polônia & 8,1 & 7,2 & 8,5 & 16,2 \\
\hline Inglaterra & 9,1 & 11,6 & 3,9 & 12,5 \\
\hline Total (\%) & 84,8 & 91,3 & 90,2 & 84,4 \\
\hline
\end{tabular}

Fonte: EUROSTAT, $2018^{13}$

Inclusive, ainda não havia sido oficialmente divulgado o fechamento do acordo, mas já se notava a mobilização de deputados do Partido Verde na Alemanha e no Parlamento Europeu e, da Associação Alemã de agricultores para, nos bastidores, impedir a ratificação do documento (BONIS, 2019).

\footnotetext{
${ }^{12}$ A agricultura foi considerada para a integração entre os Estados-membros desde a CEE. Neste aspecto, os artigos 38 a 47 do Tratado de Roma ficaram reservados ao tema e, posteriormente, foram integrados ao Tratado de Lisboa de 2009.

13 EUROPEAN UNION. Agriculture, forestry and fishery statistics, 2018. Disponível em $<$ https://ec.europa.eu/eurostat/documents/3217494/9455154/KS-FK-18-001-EN-N.pdf/a9ddd7db-c40c-48c9-

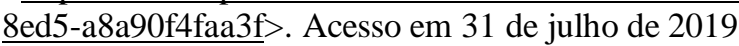




\section{CONSIDERAÇÕES FINAIS}

Finalmente, depois de 20 (vinte) anos de negociações foi anunciado oficialmente, a firma do acordo entre a União Europeia e MERCOSUL, comemorado efusivamente, pelo governo brasileiro.

Durante o processo negocial diversos impasses foram surgindo, principalmente, devido a existência de fortes assimetrias entre ambas as regiões regional, em que pese à histórica e estreita conexão da Europa com a América do Sul e o seu peso como parceiro comercial para os países da região.

Embora tenham sido anunciados os termos finais para o acordo, deve lembrar-se que há um complexo caminho para a ratificação e vigência do mesmo, ao passo que setores europeus já manifestam a sua desconfiança e a tendência de obstaculizar e/ou impedir a entrada em vigor do referido acordo.

Afinal, ao longo das negociações sempre ficou claro que enquanto os países do MERCOSUL tinham interesse em liberalizar o comércio de seus produtos agropecuários, no mercado europeu os produtores se mantem receosos quanto ao efeito do Acordo sobre a indústria regional. Para os europeus sempre houve a intenção de abrir mercado para seus bens industriais, mas com temor de produzir perda comercial para o seu setor agropecuário, sabidamente, subsidiado pela PAC.

Por outro lado, sabe-se que estados possuem interesses relacionados com o desenvolvimento nacional e as diretrizes de política exterior. Com esse intuito, os setores econômicos e políticos nacionais, notadamente a agroindústria, desenvolveram um discurso voltado para a liberalização econômica e para as reformas estruturais, visando gerar competitividade no mercado interno e produtividade para o setor exportador, construindo uma retórica que influenciasse inclusive o processo legislativo. Da mesma forma, o setor agropecuário europeu segue a mesma orientação, e vem se manifestando no sentido de pressionar politicamente os parlamentos nacionais e europeu para impedir a posterior ratificação do acordo.

Além das pressões internas de grupos de interesses nos países europeus, acresce-se no cenário internacional a guerra comercial sino-americana diante do unilateralismo norteamericano e as futuras eleições presidenciais nos Estados Unidos, bem como as eleições para os parlamentos nacionais na Europa colocam a concretização futura do acordo MERCOUL- 
União Europeia sob um caleidoscópio de variáveis, o que dificulta a previsão de um desfecho preciso para a questão. E, também, as escolhas políticas manifestadas pelo governo brasileiro podem colocar o país em rota de colisão com a efetiva ratificação do acordo, principalmente, no que concernem as questões socioambientais e trabalhistas.

\section{REFERÊNCIAS}

ASSOCIAÇÃO DE COMÉRCIO EXTEIOR DO BRASIL - AEB. Defesa Comercial e o Acordo MERCOSUL União Europeia. Disponível em

<http://www.aeb.org.br/noticias/defesa_comercial_e_o_acordo_mercosul-uniao_europeia>. Acesso em 05 de agosto de 2019.

BERRINGER, Tatiana; FORLINI, Luana. Crise política e mudança na politica externa no governo Temer: contradições no seio da burguesia interna brasileira. In: Ver. Conj. Aust. Porto Alegre. v.9. n. 48. p. 5-19. Out/dez 2018.

BONIS, Gabriel. Partido verde e agricultores alemães querem bloquear acordo EUMERCOSUL. In: BBC News, 4 de julho de 2019. Disponível em $<$ https://www.bbc.com/portuguese/brasil-48863659>. Acesso em 05 de agosto de 2019.

BUENO, Clodoaldo. O Brasil e o integracionismo: do ABC de Rio Branco a operação PanAmericana. In: A América do Sul e a Integração Regional. Brasília: FUNAG, 2012..

CARDOSO JR, Reforma do Estado e desregulamentação do trabalho no Brasil, nos anos 90. In: Ensaios FEE, Porto Alegre, v.23. n.2, p. 899-922, 2002. Disponível em $<$ https://revistas.fee.tche.br/index.php/ensaios/article/view/2046/2428>. Acesso em 31 de julho de 2019.

CARVALHO, Felipe Augusto Torres de; LEITE, Alexandre César Cunha. Acordo de Associação Inter-regional MERCOSUL - União Europeia: entraves à aprovação e perspectivas futuras. In: Século XXI, Porto Alegre, v.4 n.2. Jul-Dez, 2013. p.107-133 Disponível em: <http://sumarioperiodicos.espm.br/index.php/seculo21/article/view/1870/145> .Acesso em 06 de junho de 2019.

DATHEIN, Ricardo Integração Econômica e Politicas de Desenvolvimento: Experiências e perspectivas para a América Latina. In: Análise Econômica. Ano 25. n. 47. Setembro 2007. Porto Alegre: Faculdade de Ciências Econômicas. Disponível em <http://seer.ufrgs.br/AnaliseEconomica/article/viewFile/10880/6470>. Acesso em 20 de dezembro de 2014.

DIZ, Jamile Bergamaschine Mata; LUQUINI, Roberto de Almeida. As relações exteriores do MERCOSUL: análise das negociações com a União Europeia. In: Univ. Rel. Int, Brasília. v.9. n.1, p. 103-130, jan/jun. 2011. Disponível em <https://www.publicacoesacademicas.uniceub.br/relacoesinternacionais/article/view/1359>. Acesso em 10 de junho de 2019. 
FIESP. Documento de posição. Propostas de integração Externa da Indústria, 2014.

Disponível em <https://www.fiesp.com.br/arquivo-download/?id=159608>. Acesso em $31 \mathrm{de}$ julho de 2019.

FIESP. Acordo entre MERCOSUL e União Europeia abre oportunidade histórica para o Brasil, 2019. Disponível em <https://www.fiesp.com.br/noticias/acordo-entre-mercosul-e-ueabre-oportunidade-historica-para-o-brasil-diz-paulo-skaf/ >.Acesso em 31 de julho de 2019.

FUNDAÇÃO ULYSSES GUIMARÃES. Uma ponte para o futuro, 2015. Disponível em $<$ https://www.fundacaoulysses.org.br/wp-content/uploads/2016/11/UMA-PONTE-PARA-OFUTURO.pdf $>$. Acesso 31 de julho de 2019.

ITAMARATY. Discurso do Ministro José Serra por ocasião da cerimônia de transmissão do cargo de ministro de estado das relações exteriores. Brasília, 18 de maio de 2016. <Disponível em: http://www.itamaraty.gov.br/discursos-artigos-e-entrevistas-categoria/ministro-dasrelacoes-exteriores-discursos/14038-discurso-do-ministro-jose-serra-por-ocasiao-dacerimonia-de-transmissao-do-cargo-de-ministro-de-estado-das-relacoes-exteriores-brasilia18-de-maio-de-2016>. Acesso em 19 de agosto de 2018.

ITAMARATY. Acordo de Associação MERCOSUL-União Europeia. Resumo Informativo elaborado pelo governo brasileiro, 2019. Disponível em <http://www.itamaraty.gov.br/images/2019/2019_07_03__Resumo_Acordo_Mercosul_UE.pdf>. Acesso em 30 de agosto de 2019

LOCATEL, Celso Donizete; LIMA, Fernanda Laize da Silva. Agronegócio e poder político: políticas agrícolas e o exercício do poder no Brasil. In: Sociedade e Território. v. 28. n.2. p.57-81. Natal, Dez/2016. Disponível em: $<$ https://periodicos.ufrn.br/sociedadeeterritorio/article/download/11583/8166/>. Acesso em 01 de agosto de 2019.

MACHADO, Audálio José Pontes; NÓBREGA, Natasha Coelho Figueiredo. Plata o plomo? Desempenho econômico dos países sul-americanos pós-regimes autoritários. In: $40^{\circ}$ Encontro Anual da ANPOCS. Caxambu, 2016. Disponível em $<$ http://www.anpocs.com/index.php/encontros/papers/40-encontro-anual-da-anpocs/st10/st10-7/10233-plata-o-plomo-desempenho-economicos-dos-paises-sul-americanos-posregimes-autoritarios?path=40-encontro-anual-da-anpocs/st-10/st10-7>. Acesso em 15 de junho de 2019.

MANFRINI, Sandra; WARTH, Anne. Indústria e CNT dão apoio ao impeachment de Dilma. Estado de São Paulo de 13 de abril de 2016. Disponível em Acesso em $<$ https://politica.estadao.com.br/noticias/geral,industria-e-cnt-dao-apoio-ao-impeachment-dedilma,1855909>. Acesso em 31 de julho de 2019

MAGNOLI, Demétrio; ARAÚJO, Regina. O projeto da ALCA: Hemisfério Americano e MERCOSUL na ótica do Brasil. São Paulo: Moderna, 2003. 
MATHIAS, Meire. Sob o prisma dos interesses: a política externa brasileira e a Confederação Nacional da Indústria. / Meire Mathias. 243 p. Campinas, SP: 2011.. Tese (doutorado) Universidade Estadual de Campinas. Instituto de Filosofia e Ciências Humanas.

MUNHOZ, Dércio Garcia. América Latina Ortodoxia Econômica e Dependência Financeira. In: R. Econ. Contemp, Rio de Janeiro, 6. n.1. 2002. P. 7-23. Disponível em http://www.ie.ufrj.br/images/pesquisa/publicacoes/rec/REC\%206/REC_6.1_01_America_lati na_ortodoxia_economica_e_dependencia_financeira.pdf. Acesso em 20 de junho de 2019.

MERCOSUL. Uruguai assume a Presidência Pro Tempore do MERCOSUL. Disponível em $<$ https://www.mercosur.int/pt-br/uruguai-assume-a-presidencia-pro-tempore-do-mercosul/> . Acesso em 01 de agosto de 2019

OLIVEIRA, Odete Maria de. A integração bilateral Brasil-Argentina: tecnologia nuclear e MERCOSUL. In: Revista Brasileira de Politica Internacional. 1998. n.41 p. 5-23

OLIVEIRA JUNIOR, Joaner Campello de; VAZ, Natália Carolina de Oliveira. Os projetos de infraestrutura da IIRSA e a violação dos direitos indígenas. In: Aracê - Direitos Humanos em Revista. Ano 4. n. 5. Fevereiro de 2017. p. 202-218. Disponível em <https://arace.emnuvens.com.br/arace/article/view/142/77>. Acesso em 30 de julho de 2019.

ROCHA, Maurício Santoro. Desenvolvimento como Integração. In: O Brasil e a América do Sul: desafios no século XXI. Brasília: Fundação Alexandre Gusmão. Instituto de Pesquisa de Relações Internacionais, 2006.

SANTOS, Lucas Bispo; MENGANA, Milagro. A negociação do Acordo MERCOSUL-União Europeia: Ímpetos renovados?, 2016. In: Observatório Regionalismo. Grupo de Pesquisa vinculado a REPRI. Disponível em <http://observatorio.repri.org/artigos/a-negociacao-doacordo-mercosul-uniao-europeia-impetos-renovados/>. Acesso em 01 de agosto de 2019.

SANTOS, Lucas Bispo. As negociações do Acordo de Associação Inter-regional MERCOSUL-União Europeia: o posicionamento brasileiro e seus ímpetos de negociação. 2017. In: XVI Congresso Internacional FoMerco. Integração regional em tempos de crise: desafios políticos e problemas teóricos. Disponível em <http://www.congresso2017.fomerco.com.br/resources/anais/8/1505915802_ARQUIVO_Luc asBispodosSantos-Fomerco.pdf>. Acesso em 01 de agosto de 2019.

SAVINI, Marcos. As negociações comerciais entre MERCOSUL e União Europeia. In: Rev. Bras. Polít. Int. 44 (2). P. 109-125, 2001. Disponível em $<$ http://www.scielo.br/scielo.php?script=sci_arttext\&pid=S0034$73292001000200006 \& \operatorname{lng}=e n \& n r m=i s o>$.Acesso em 15 de junho de 2019

SUNKEL, Osvaldo. Desarrollo e integración regional: outra oportunidade para uma promessa incumplida. In: Revista de La CEPAL. 1998. Numero Extraordinário. p. 229-243. 